\title{
Automatic Railway System
}

\author{
Leena G., PhD \\ Dept. of EEE, MRIU \\ Faridabad, Haryana, India
}

\author{
Chetan Singh Vidawat \\ Dept. of EEE, MRIU \\ Faridabad, Haryana, India
}

\author{
Nitesh Jha \\ Dept. of EEE, MRIU \\ Faridabad, Haryana, India
}

\begin{abstract}
The aim of this paper is to automate various operations related to opening and closing of railway gates in order to minimize the accidents at unmanned railway gates. This automatic system also identifies the person who is unnecessarily pulling the chains and alerts the station master about the position of train using GSM technique. It also identifies unwanted obstruction in the track by anti-collision technique and detects the breakage in track. This automatic railway system reduces the waiting time of road passengers at the railway crossings since it will identify the arrival of the train and there by closing the gate when needed.
\end{abstract}

\section{Keywords}

GSM technique, Railway joint track detection, Anti-collision technique, RFID technique, Chain- pulling system

\section{INTRODUCTION}

Railways being one of the safest and cheapest modes of transportation are preferred over all the other means of transport. So, it is essential to maintain and improve the current level of safety. A safe railway is more efficient and also a more attractive transport choice, enabling society to address the environmental and economic challenges of the 21 st century. Railway safety is a crucial aspect of rail operation the world over. There are regular newspaper reports about railway accidents occurring at different railway level crossings and many people lost their lives in such accidents.

Although the development of railways took place rapidly, still there are enormous problems in the path of its steady growth. The major problem faced by Indian railways is that the tracks are old and obsolete. These old tracks cause many serious railway accidents. This has also resulted in speed restrictions. Virtually, in every new timetable, running time of all trains has been increased while railways in other advanced countries are reducing it drastically Another problem that is being faced in India is that a large number of passengers travel without purchasing tickets. The incidence of railway accidents in India is greater as compared to other countries of the world. Accidents also occur due to the errors and negligence of the employees.

There is a lack of modern management as railways failed to provide adequate incentives to attract suitable talent. In addition to it, it could not make economic analysis for perspective planning tariff. The rolling stock technology is absolutely outmoded. The system is beset with excessive staff and manpower development has not kept pace with technology up gradation. This has made railways incapable of coping with increased transport demand and of raising and improving the traffic volume and flows at lower unit cost of operation.

Most of the railway lines are single lines which create great inconvenience to the railway organization and passengers. The railway transport has lagged behind the requirement due to inadequate investment. The shortcoming has been highlighted by different committees; the National Transport Policy Committee, the Rail Tariff Enquiry Committee and the Railway Reforms Committee. The competition with road transport is growing in intensity, both in passenger and in goods transport. The lack of coordination between railways and road transport has lowered the earning capacity of the railways. This has further caused delay in traffic movement and inconvenience to passengers.

It is reported in daily newspapers that many rail accidents occur at unmanned railway crossings. This is mainly due to the carelessness in manual operations or lack of workers, unnecessary pulling of chain and long waiting at the railway crossing.

Indian Railway has developed a vandal-proof warning system for unmanned level crossings which is working satisfactorily for the last three months on Coimbatore-Mettupalayam section [1]. In Indian railways, there are a total of 28,607 level crossings across the country of which 19,267 are manned and 9340 are unmanned. According to the action plan, the railways is focusing on eliminating almost all the unmanned level crossing in the next 3-4 years [2]. With this focus it is desirable to study various techniques to control the operation of gates at level crossings. Many journal papers are available which proposes automated railway gate system [3-7]. These papers discuss different options such as automatically controlled railway gate at the level crossing, railway track switching mechanism and the movement of the train using sensors, micro controllers for reduction of railway accidents and controller for stepper motor which operates the opening and closing of railway gates at the railway crossings.

$\mathrm{K}$ Vidyasagar et al [8] designed a system which uses ultrasonic sensors to identify objects on the track and accordingly control signal is generated and transferred to the control room via communication protocol to control the movement of train in railway track. Pwint et al [9] describes the automatic railway gate control system using PIC microcontroller for saving precious human lives and preventing major disasters in railway track. An Arduino based control system for the opening and closing of railway gates with IR sensors for detection of train is proposed by Krishnamurthi et al [10]. A detailed introduction about the technology adopted in railways is described with the disadvantages of manually operated railway warning systems at level crossings by Dewangan et al [11]. Mahmud et al [12] discuss the design and implementation of an automated railway gate control system which detects the train by analyzing the reflected waves, produces alarm, controls light signal and gate. 
In the present paper it is tried to automate all the necessary operations in railways i.e. controlling of gates, identifying the person who is unnecessarily pulling the emergency chain, alerting the station master about the location of train, identification of crack in railway track and anti-collision technique.

In order to reduce accidents in unmanned railway crossings it is proposed to have an automatic gate control system at the crossings. The arrival of the train at the crossing in terms of distance is calculated and informed to the staff of railways through GSM which enables lesser closing times of the railway gates for the road transport users. In addition to this, the fault in railway track as well as a message is carried to the station master when there is another train on the same track.

\section{HARD WARE IMPLEMENTATION}

The system developed has the following features:

Distance measuring between arriving train and crossing platform in kilometers using magnetic reader which are placed after few kilometer from one another, Notifying station master about status of arriving train using GSM technique so that prior information can be given for that gate opening and closing so as to cause less inconvenience to the public, Automatic railway gate operation at the crossing (unmanned), RFID technique used for emergency stopping instead of chain-pulling system so that unnecessarily chain pulling can be avoided. Using this a record of the person who is pulling the chain is kept in case of emergency. Most of the railway accident took place because of broken railway track, this result in loss of property and human which can be identified by means of sensors. Also an anti-collision module is developed to avoid head on collision on railway tracks.

The main block diagram of the developed automatic railway system is given in Fig.1. The main components of the overall system are power supply unit, microcontroller, magnetic reader, relays, IR sensors, RFID module, GSM module and anti collision modules

\subsection{S52 Microcontroller}

The AT89S52 is a low-power, high-performance CMOS 8-bit microcontroller with $8 \mathrm{~K}$ bytes of in-system programmable Flash memory. The device is manufactured using Atmel's high-density nonvolatile memory technology and is compatible with the industry standard 80C51 instruction set and pin out. The AT89S52 provides the following standard features: $8 \mathrm{~K}$ bytes of Flash, 256 bytes of RAM, 32 I/O lines, Watchdog timer, two data pointers, three 16-bit timer/counters, a six-vector two-level interrupt architecture, a full duplex serial port, on-chip oscillator, and clock circuitry.

\subsection{Magnetic Reader}

Magnetic reader is the device used for measuring the distance by sensing the magnet. Every vehicle has a magnetic field, a vehicle's magnetic field has an inverse relationship with distance at small distances [13]. The relationship provides a way to estimate a vehicle's position using its magnetic field when the vehicle is less than a few meters away, which could be useful for detecting imminent collisions just before they occur. The sensors will provide information on the relative velocity and position of the impending crash on the vehicle.

\subsection{Motor}

It is effectively design with D.C. motors, it is necessary to understand their characteristic curves. For every motor, there is a specific Torque/Speed curve and Power curve. The torque is inversely proportional to the speed of the output shaft. In other words, there is a tradeoff between how much torque a motor delivers, and how fast the output shaft spins.

\subsection{Power Supply}

The power supply setup for the project consists of a step down transformer to decrease the level of voltage and current and rectifier circuit, filter and voltage regulator is used to convert ac to dc of $12 \mathrm{~V} / 5 \mathrm{~V}$

\subsection{Voltage Regulator}

Regulated power supply is an electronic circuit that is designed to provide a constant dc voltage of predetermined value across load terminals irrespective of ac mains fluctuations or load variations. The two main parts of a regulated power supply are a simple power supply and a voltage regulating device. The power supply output is given as input to the voltage regulating device that provides the final output.

\subsection{Relay}

Relay is an electrically switching device based on the principle of electromagnetism. It consists of an electromagnet made from iron wound with hundreds of fine copper wire. When electricity is supplied to the wire, the rod becomes magnetic. A movable contact arm above the rod is then pulled toward the rod until it closes a switch contact. When the electricity is switched off, a small spring pulls the contact arm away from the rod until it closes a second switch contact. By means of relay, a current circuit can be broken or closed in one circuit with the change of current in another circuit.

\subsection{GSM Module}

A GSM/GPRS module assembles a GSM/GPRS modem with standard communication interfaces like RS-232 (Serial Port), USB etc., so that it can be easily interfaced with a computer or a microprocessor / microcontroller based system. The power supply circuit is also built in the module that can be activated by using a suitable adaptor.

\subsection{RFID Chain Pulling Module}

An RFID system consists of two separate components: a tag and a reader. Tags are analogous to barcode labels, and come in different shapes and sizes. The tag contains an antenna connected to a small microchip containing up to two kilobytes of data. The reader, or scanner, functions similarly to a barcode scanner; however, while a barcode scanner uses a laser beam to scan the barcode, an RFID scanner uses electromagnetic waves.

\subsection{Anti-Collision Module}

IR Sensors work by using a specific light sensor to detect a select light wavelength in the Infra-Red (IR) spectrum. By using an LED which produces light at the same wavelength as what the sensor is looking for, you can look at the intensity of the received light. When an object is close to the sensor, the light from the LED bounces off the object and into the light sensor. This results in a large jump in the intensity, which we already know can be detected using a threshold.

\subsection{Software Implementation}

The software used in the system is Embedded ' $\mathrm{C}$ ' programming with Keil compiler.

\section{DESIGN AND TESTING}

Various features are developed in this system i.e. unmanned gate control, track joint detection, GSM technique for delivering actual status of train to station master, RFID 
technique used for chain pulling to identifying the person who pulled the chain and anti-collision technique for safety measures, and distance measurement. Initially the power supply was designed for proper voltage and current used for whole circuitry. This power further sends to the different components used in the circuit for designing the automatic railway system. For the operation of opening and closing of railway gates a dc motor is controlled using 89s52 microcontroller.

Magnetic readers are placed at certain distances in the track. When the train crosses this magnetic reader, the distance measured is transmitted to the station master through GSM module which is connected to microcontroller. RFID module is developed and connected to microcontroller to avoid the unnecessary chain pulling. In the proposed automatic railway system the chain pulling device is replaced by RFID system. The passengers use the identified cards to pull the chain by which the identity of the passengers is known and hence unwanted chain pulling is reduced. An anti-collision module is developed using IR sensor placed on the train. It will identify the objects in front of the train and correspondingly the train is stopped. The automatic railway system proposed with the above features was successfully tested on a prototype model developed and shown in Fig.2

\section{CONCLUSIONS}

It is a challenge to save the human life and vehicles from miserable train accidents in the era of modern science and technology. It is tried to automate various operations related to opening and closing of railway gates in this paper. Thus accidents are avoided at places where there is no person managing the railway crossing gates. The system also identifies the person who is unnecessarily pulling the chains. It alerts the station master about the location of train using GSM technique, railway joint track detection, This system reduces the waiting time of road passengers at the railway crossings since it will identify the arrival of the train and there by closing the gate when needed. The obstacle detection system is very helpful to avoid accidents while the train is moving through the forest. It will save the life of wild animals and also reduce the accidents in track. The present system is a proto type model which can be expanded to be operational in actual real time systems. Further identification of unwanted chain pulling can be done by linking Adhaar card with the RFID technique.

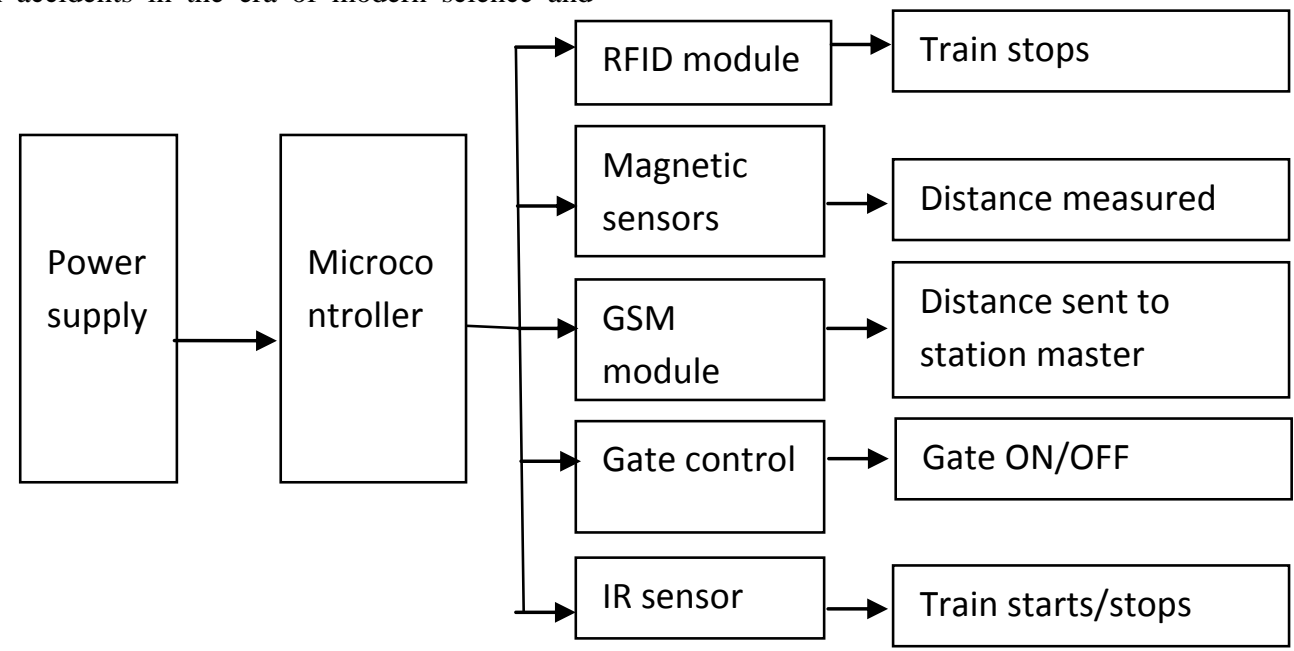

Fig 1: Block diagram of automatic railway system

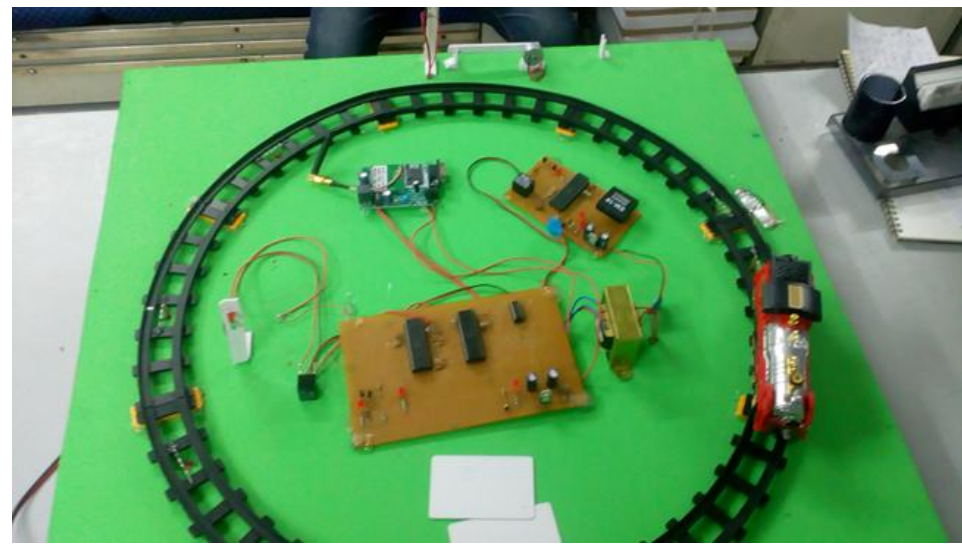

Fig. 2 Developed model of the automatic railway system 


\section{REFERENCES}

[1] Railways to eliminate over 6,000 unmanned level crossings, article in the Indian Express, 30th July 2016 by PTI.

[2] Indian Railway develops warning system for unmanned level crossings, article in Times of India, 25th October 2015 by PTI

[3] J. Banuchandar, V. Kaliraj, P. Balasubramanian, S. Deepa, N. Thamilarasi,“ Automated Unmanned Railway Level Crossing System”, International Journal of Modern Engineering Research (IJMER)Volume.2, Issue.1, JanFeb 2012, pp-458-463.

[4] Ahmed Salih Mahdi. Al-Zuhairi,"Automatic Railway Gate and Crossing Control based Sensors \& Microcontroller", International Journal of Computer Trends and Technology (IJCTT) - Volume 4 Issue 7-July 2013, pp. 2135-2140.

[5]Krishna, Shashi Yadav and Nidhi, "Automatic Railway Gate Control Using Microcontroller”, Oriental Journal Of Computer Science \& Technology, Vol.6, No.4, December 2013, pp 435-440.

[6] Acy M. Kottalil ,Abhijith S, Ajmal M M, Abhilash L J.,AjithBabu., Automatic Railway Gate Control System, International Journal of Advanced Research in Electrical, Electronics and Instrumentation Engineering, vol.3,issue 2,Feb 2014, pp 7619-7622.

[7]Swati Rane, MayuriPendhari, PoojaPatil, PrakashSakari, YashmithShetty, Automatic Railway Gate Control and Track switching with automated train, International
Journal of Science, Engineering and Technology Research (IJSETR), Volume 4, Issue 4,April 2015 ,pp 1062-1066.

[8] K. Vidyasagar, P. SekharBabu, R. RamPrasad,Anti Collision and Secured Level Crossing System, International Journal of Computer Applications Volume 107 ,No 3, December 2014, pp.1-4

[9] HninNgwe Yee Pwint, ZawMyoTun, HlaMyoTun, Automatic Railway Gate Control System Using Microcontroller, International Journal of Science, Engineering and Technology Research (IJSETR), Volume 3, Issue 5, May 2014 ,pp 1547-1551

[10] Karthik Krishnamurthi, Monica Bobby, Vidya V, Edwin Baby,Sensor based automatic control of railway gates,International Journal of advanced Research in Computer Engineering and Technology, vol.4,issue 2 Feb2015, pp.539-543

[11] Atul Kumar Dewangan, Meenu Gupta, Pratibha Patel, Automation of Railway Gate Controller using Micro controller, International Journal of Engineering Research and Technology, 2012, pp1-8.

[12] Saifuddin Mahmud, IshtiaqReza Emon,, Md. MohaiminBillah, Automated Railway gate controlling system, International Journal of Computer trends and Technology, volume 27,no.1 september 2015, pp.1-5.

[13] S. Taghvaeeyan and R. Rajamani. "Use of vehicle magnetic signatures for position estimation." Applied Physics Letters 99, (2011) no.13,pp..13401-13401-3. 